\title{
Endoscopic Study of Normal Trachea and Bronchus through Tracheobronchoscope in 60 Healthy Dogs
}

\author{
D.U. Lokhande, L.B. Sarkate and G.U. Yadav* \\ Department of Surgery and Radiology, Bombay Veterinary College Parel Mumbai 12 \\ (Maharashtra Animal and Fishery Sciences University, Nagpur-440006), India \\ *Corresponding author
}

\begin{tabular}{l} 
Ke y w o r d s \\
$\begin{array}{l}\text { Tracheo- } \\
\text { bronchoscopy, } \\
\text { fiberscope, sternal, } \\
\text { epiglottis, carina }\end{array}$ \\
Article Info \\
$\begin{array}{l}\text { Accepted: } \\
12 \text { October } 2018 \\
\text { Available Online: } \\
10 \text { November } 2018\end{array}$ \\
\hline
\end{tabular}

\section{A B S T R A C T}

Diagnostic imaging enabled the surgeon for the visual evaluation of normal and abnormal anatomy of the region and thus helped in accurate diagnosis of many diseases. Tracheobronchoscopy was found more feasible and advantageous in diagnosis of respiratory disease as compared with that of physical examination, haematology and radiography and allows descriptive or photographic documentation of findings. It has advantage of providing accurate diagnosis through biopsy, cytological examination and fluid estimations in dog. The tracheobronchoscopy was performed by fiberscope (Olympus GIF type XP 20)having an ultra-slim insertion tube of $7.9 \mathrm{~mm}$ outer diameterand $102 \mathrm{~cm}$ working length with $2.0 \mathrm{~mm}$ width instrument channel. The dog was placed in sternal recumbent position after proper anaesthesia and the neck was supported with the soft cushion. The tracheal mucus membrane was found pink ( 37 cases) to red ( 23 cases) in color with fine network of sub mucosal vessels and was glistering. The dorsal tracheal membrane was found tight in all the cases. The mean distance of epiglottis from upper incisors was found $9.77 \pm$ $0.33,15.05 \pm 0.35$ and $17.67 \pm 0.44 \mathrm{~cm}$ in small, medium and large sized dogs respectively. The distance of part was significantly different $(\mathrm{P}<0.05)$ in small, medium and large size dogs, respectively. The mean distance $(\mathrm{cm})$ of carina from upper incisors was measured as $31.87 \pm 0.96,40.65 \pm 0.33$ and $53.57 \pm 0.90 \mathrm{~cm}$ in small, medium and large sized dog respectively.

\section{Introduction}

Diagnosis of the disease is not only important for the treatment but it also plays a key role in its post-operative management. In olden days, surgery performed to treat the diseases, had very high rate of morbidity and mortality due to late diagnosis or improper diagnosis. Diagnostic imaging enabled the surgeon for the visual evaluation of normal and abnormal anatomy of the region and thus helped in accurate diagnosis of many diseases.

Endoscopy allows descriptive or photographic documentation of findings and has advantage of providing accurate diagnosis through biopsy, cytological examination and fluid estimations (Strombeck and Guilford, 1991). 
The techniques of endoscopic diagnosis and treatment of respiratory tract diseases has been recently reestablished in human and veterinary medicine. Bronchoscopy is a demanding field for understanding kinetics of pathological processes in pulmonary tissue (Rajmaki et al., 2001). Similarly, tracheobronchoscopy was found more feasible and advantageous in diagnosis of respiratory disease as compared with that of physical examination, haematology and radiography in dog (Passos et al., 2004). Caccamo et al., (2007) performed bronchoscopy according to bronchoscopic nomenclature as previously described by Amis and Mc Kiernan (1986) for the dogs. They also developed bronchoscopic map of the feline bronchial tree and a photographic atlas of bronchoscopy of the healthy cats. However availability of tracheobronchoscopic images of normal canine trachea and bronchus is still limited for accurate diagnose of tracheobronchial diseases. Therefore the study was performed and endoscopic images of normal canine trachea and bronchus were documented for the guldens / reference to the research workers and clinicians.

\section{Materials and Methods}

The study was conducted on 60 clinical cases presented for various miner surgical procedure like castration, small growths removal or treatment of simple wounds, The cases were examined physically and Blood was evaluated for CBC, LFT and KFT and the dogs with normal values were selected.

The tracheobronchoscopy was performed as described by Padrid and Mc Kiernan (1999) with the help of fiberscope (Olympus GIF type XP 20) having an ultra-slim insertion tube of $7.9 \mathrm{~mm}$ outer diameter and $102 \mathrm{~cm}$ working length with $2.0 \mathrm{~mm}$ width instrument channel. After anaesthesia, the dog was placed in sternal recumbent position and support was given to the ventral neck with soft cushion. The mouth was held open by fixing upper and lower canine teeth of one side with a piece of stainless steel pipe and insertion tube was passed between the vocal folds by pressing epiglottis downwards. The trachea was observed for color, vascularity and movement of dorsal membrane. The insertion tube was advanced further till carina was visualized.

The tip was then deflected to the left side and left principal bronchus was visualized. After withdrawing the scope to carina, the tip was redirected towards right side and right principal bronchus was visualized. In large breeds the scope was inserted till the visualization of deep bronchioles and the same was recorded.

\section{Results and Discussion}

Insertion of tracheobronchoscope up to the epiglottis (Fig. 1) was found easy but its entry into the vocal cord requires several attempts initially. This is because of the fact that this technique requires experience and it usually comes with its routine use and practice. During initial period, lack of experience brought these difficulties while passing insertion tube into the trachea. Entry of insertion tube from vocal cord (Fig. 2) to carina was found without any difficulty. The tracheal rings were easily identified through tracheobronchoscope (Fig. 3 and 4).

The endoscopic appearance of normal healthy trachea from epiglottis to bronchi in different sizes of dogs in given in Figure 1 to 6 . The description for the same is given in Table 1 .

The color of mucus membrane varied from pink (37 cases) to red (23 cases) and was glistering. None of the cases showed mucus or free fluid of any kind, except in four cases where very small quantity of mucoid strings was noted. 


\section{Endoscopic appearance of Trachea and Bronchi}

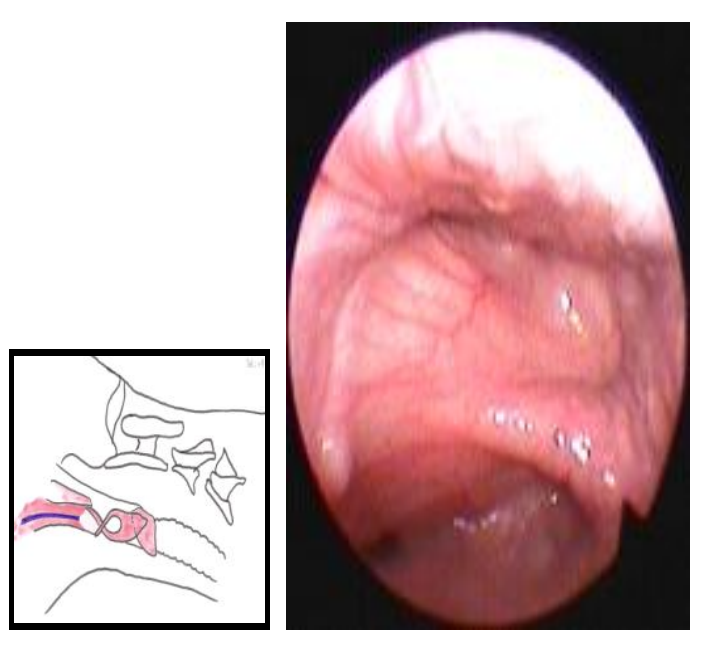

Fig. 1: Endoscopic appearance of epiglottis with approximate location of tube
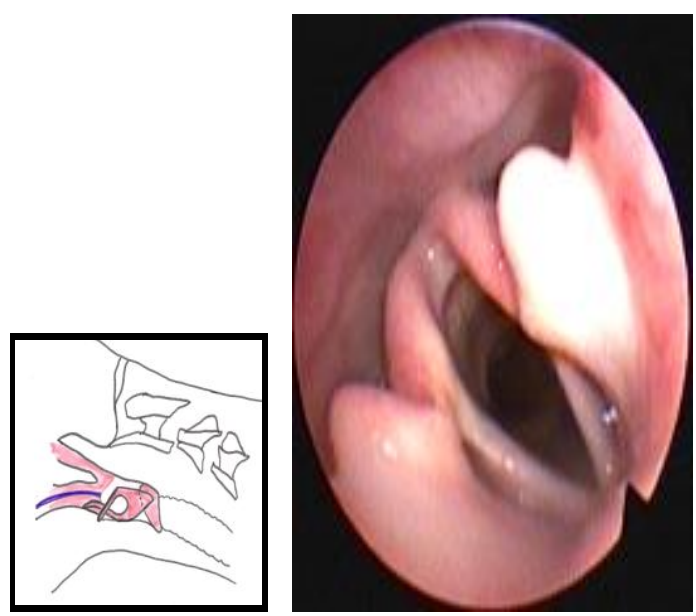

Fig. 2: Endoscopic appearance of cuniform process, corniculate process and vocal folds with approximate location of tube
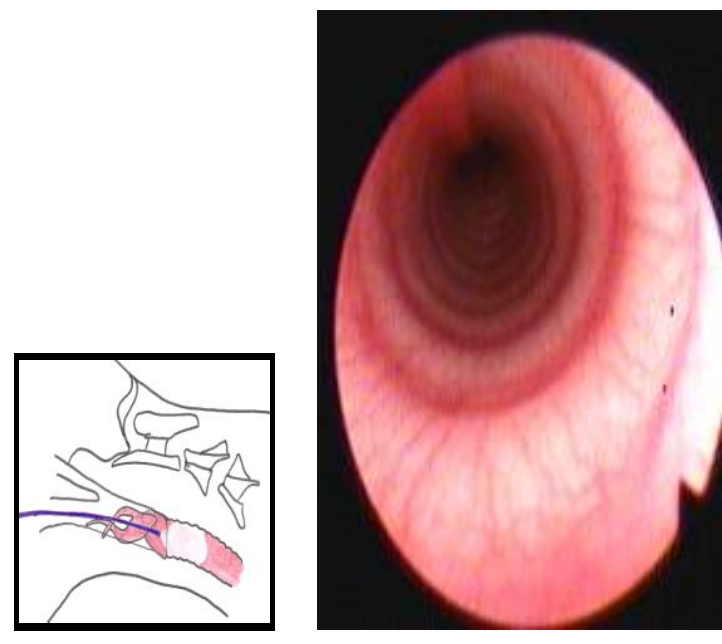

Fig. 3: Endoscopic appearance of anterior tracheal opening with dorsal tracheal membrane at 12 o'clock position \& approximate location of tube

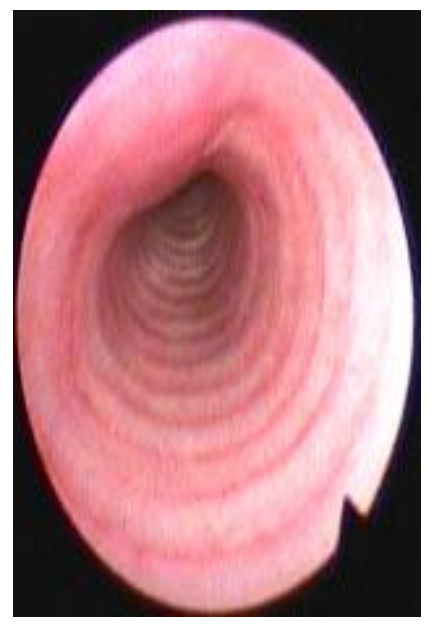

Fig. 4: Endoscopic appearance of mid trachea showing tracheal rings and thin strip like dorsal tracheal membrane at 11 o'clock position \& approximate location of tube 

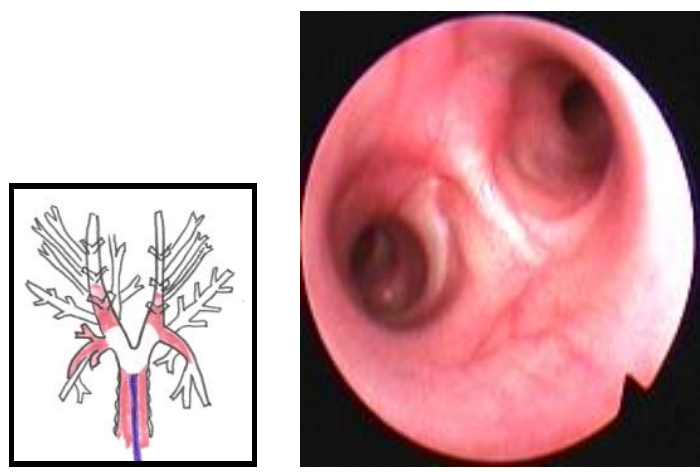

Fig. 5: Endoscopic appearance of carina with left and right primary bronchi and dorsal tracheal membrane at 11 o'clock position \& approximate location of tube
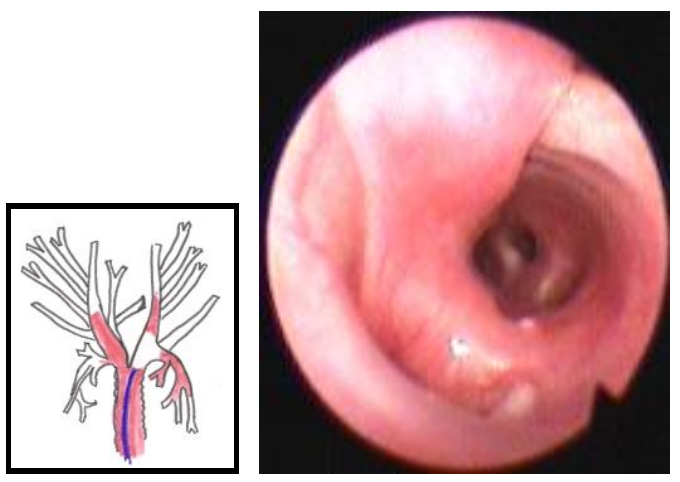

Fig. 6: Endoscopic appearance of the left principle bronchus with approximate location of tube
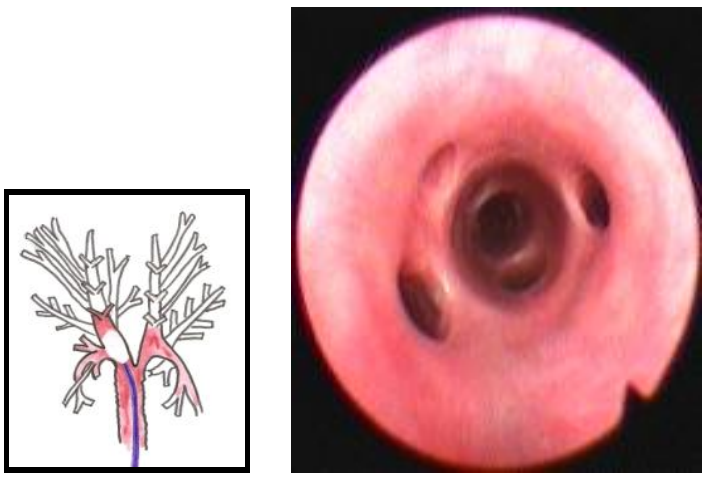

Fig. 7: Endoscopic appearance of the right principle bronchus with multiple bronchial openings \& approximate location of tube
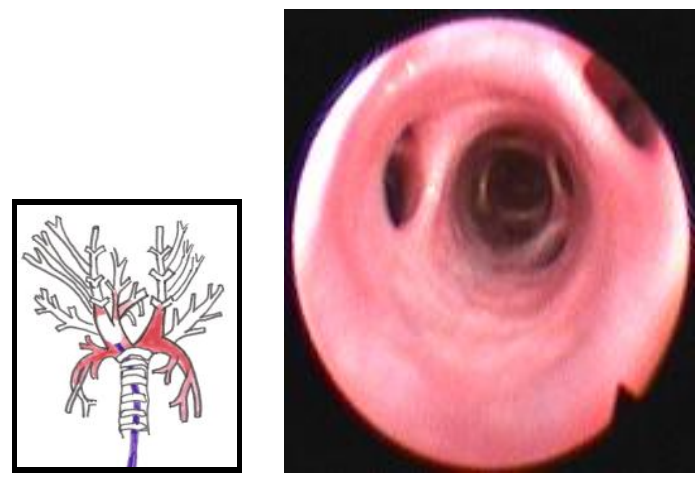

Fig. 8: Endoscopic appearance of multiple bronchial openings with approximate location of tube

Table.1 Description of endoscopic appearance of normal healthy trachea Visualized in different cases

\begin{tabular}{|c|c|c|c|c|c|c|c|c|}
\hline \multirow[t]{2}{*}{$\begin{array}{l}\text { Endoscopic } \\
\text { description }\end{array}$} & \multicolumn{2}{|c|}{$\begin{array}{l}\text { Color of mucous } \\
\text { membrane }\end{array}$} & \multicolumn{2}{|c|}{ Contents } & \multicolumn{2}{|c|}{$\begin{array}{l}\text { Dorsal } \\
\text { tracheal } \\
\text { membrane }\end{array}$} & \multicolumn{2}{|c|}{$\begin{array}{l}\text { Sub mucosal } \\
\text { blood vessels }\end{array}$} \\
\hline & Pink & Red & $\mathrm{P}$ & A & Tight & lose & $\mathrm{P}$ & $\mathbf{A}$ \\
\hline No. of cases & 37 & 23 & $\begin{array}{c}04 \\
\text { (mucus) }\end{array}$ & 44 & 60 & -- & 60 & - \\
\hline
\end{tabular}

P: Present, A: Absent. 
Table.2 Mean \pm SE values of distance $(\mathrm{cm})$ of different part/structures of respiratory tract from upper incisors in different size of dog was as below

\begin{tabular}{|c|c|c|c|c|}
\hline $\begin{array}{l}\text { Sr. } \\
\text { No. }\end{array}$ & Part/structure & $\begin{array}{l}\text { Small } \\
\text { size }\end{array}$ & $\begin{array}{l}\text { Medium } \\
\text { size }\end{array}$ & $\begin{array}{l}\text { Large } \\
\text { size }\end{array}$ \\
\hline 1 & Epiglottis & $9.77^{\mathrm{c}} \pm 0.33$ & $15.05^{b} \pm 0.35$ & $17.67^{\mathrm{a}} \pm 0.44$ \\
\hline 2 & Cuneiform Process & $11.17^{c} \pm 0.33$ & $17.02^{b} \pm 0.39$ & $19.72^{\mathrm{a}} \pm 0.43$ \\
\hline 3 & Vocal Fold & $11.70^{c} \pm 0.33$ & $17.82^{b} \pm 0.42$ & $20.42^{\mathrm{a}} \pm 0.47$ \\
\hline 4 & Carina & $31.87^{c} \pm 0.96$ & $40.65^{b} \pm 0.33$ & $53.57^{\mathrm{a}} \pm 0.90$ \\
\hline 5 & Left Principal Bronchi & $32.97^{c} \pm 0.95$ & $42.82^{b} \pm 0.31$ & $56.42^{\mathrm{a}} \pm 0.90$ \\
\hline 6 & Right Principal Bronchi & $32.82^{c} \pm 0.95$ & $42.95^{b} \pm 0.33$ & $56.42^{\mathrm{a}} \pm 0.90$ \\
\hline
\end{tabular}

Means bearing same superscript in each row do not differ significantly $(\mathrm{P} \leq 0.05)$.

Table.3 Distance $(\mathrm{cm})$ of carina from upper incisors and approximate length of insertion tube

\begin{tabular}{|l|l|l|l|}
\hline $\begin{array}{l}\text { Sr. } \\
\text { No. }\end{array}$ & Size of dog & Carina & $\begin{array}{l}\text { Approx. Length } \\
\text { of insertion tube } \\
\text { required }(\mathrm{cm})\end{array}$ \\
\hline 1 & Small size & $31.87 \pm 0.96$ & 50 \\
\hline 2 & Medium size & $40.65 \pm 0.33$ & 50 \\
\hline 3 & Large size & $\mathbf{5 3 . 5 7 \pm 0 . 9 0}$ & $\mathbf{6 0 - 7 0}$ \\
\hline
\end{tabular}

The dorsal tracheal membrane was found tight (Fig. 4) and fine network of sub mucosal blood vessels were seen in all the cases (Fig. 3 and 5). The findings of the present study are in accordance with Nakamura et al., (1988) and Padrid and Mc Kiernan (loc cit). It is interesting to note that tracheal bifurcation with carina was found asymmetrical.

The left principle bronchus was noted with acute angle (Fig. 5) as compared to that of right one. Sweeney et al., (1992) and Freeman et al., (1993) also recorded similar observation in horses. The scope was easily entered up to the primary bronchus in small and medium size dogs and up to secondary bronchus in large size dog however it was found confusing about the particular bronchus or airway segment in bronchial tree. The bronchus was pink to bluish in color (Fig. 7 and 8) with seven cases showed mucous in few bronchi, however total obliteration of an air way was not seen even in a single case.
The mean distance $(\mathrm{cm})$ of different part/structure of respiratory tract from upper incisors in different size of dogs measured by tracheobronchoscopy is given in Table 2.

The mean distance of epiglottis from upper incisors was $9.77 \pm 0.33,15.05 \pm 0.35$ and $17.67 \pm 0.44 \mathrm{~cm}$ in small, medium and large sized dogs respectively. The distance of part was significantly different $(\mathrm{P}<0.05)$ in small, medium and large size dogs, respectively. The information of distance of part from upper incisors was studied in order for knowing the requirement of length of insertion tube in different sizes of dogs viz. small, medium and large. It was also found useful to confirm the location of tip of insertion tube in different organs and also in description of position and length of lesions as well as in detection of anatomical abnormalities by endoscopy.

The observations are in accordance with the findings of Strombeck and Guilford (loc cit). 
The length of insertion tube required for tracheobronchoscopy varied in different sizes of dogs and it depends on the approximate distance of carina from upper incisors. Depending on the distance of carina from upper incisors, approximate length $(\mathrm{cm})$ of insertion tube required for tracheobronchoscopy was calculated and is given in Table 3.

The mean distance $(\mathrm{cm})$ of carina from upper incisors was measured as $31.87 \pm 0.96,40.65$ \pm 0.33 and $53.57 \pm 0.90 \mathrm{~cm}$ in small, medium and large sized dog respectively. From the above study it was found that the scope with insertion tube of length approximately $50 \mathrm{~cm}$ is sufficient for small and medium size dogs whereas $60-70 \mathrm{~cm}$ long insertion tube is necessary for large sized dogs.

\section{References}

Amis, T. C. and B. C. Mc Kiernan, (1986) Systemic identification of endobronchial anatomy during bronchoscopy in the dog. Am. J. Vet. Res. 47: 2649-2657.

Caccamo, R., D. C. Twedt, P. Buracco and B. C. Mc Kiernan, (2007) Endoscopic bronchial anatomy in the cat. J. Feline Med. Surg. 9 (2): 140-149. [Abst, http://www.ncbiin/mm.nih.gov/pubmed/ 17241804].

Freeman, K. P., J. F. Ruszel, J. M. Mc Clure, R. Mannsman, P. E. Patton and S. Naile
(1993). A review of cytological specimens from horses with and without clinical signs of respiratory disease. Equine Vet. J. 25 (6): 523-526.

Nakamura, T., S. Yoshino, E. Iida and S. Ichikawa (1988) Change in the trachea with various anaesthetics in the dog. Bulletin of Azabu University, Vet. Med. 7 (2): 69-74.

Padrid, P. A. and B. C. Mc Kiernan (1999) Endoscopy of the Upper Respiratory tract of the Dog and Cat. In: Tams T. R. (Ed). (1999) Small Animal Endoscopy, $2^{\text {nd }}$ ed. Mosby. Inc. St. Loius, Missouri pp 377-396.

Passos, R. F. B., J. O. Aquino, G.G. Oliverira, K. L. Sanches and C. L. Maniscalco (2004) Viability of the inspection tracheobronchic for video endoscopy in dogs. Brazilian J. Vet. Res. Ani. Sci. 41 (5): 344-348.

Rajmaki, M. M., A. K. Jarvin, A. M. Seppo, S. S. Paivi and Maisi (2001) Effect of repetitive bronchoalveolar lavage on cytology findings in healthy dogs. Am. J. Vet. Res. 62 (1): 13-17.

Strombeck, D. R. and W. G. Guilford (1991) Small Animal Gastroenterology, $2^{\text {nd }}$ Ed. Wolfe Publishing Ltd. London. pp 119 128.

Sweeney, C. R., J. Weiher, J. Baez and S. R. Lindborg (1992) Bronchoscopy of the horse. Am. J. Vet. Res. 53 (10): 19531956.

\section{How to cite this article:}

Lokhande, D.U., L.B. Sarkate and Yadav, G.U. 2018. Endoscopic Study of Normal Trachea and Bronchus through Tracheobronchoscope in 60 Healthy Dogs. Int.J.Curr.Microbiol.App.Sci. 7(11): 1340-1345. doi: https://doi.org/10.20546/ijcmas.2018.711.156 